\title{
Chemiluminescence and Superoxide Production by Myeloperoxidase-Deficient Leukocytes
}

\author{
Henry Rosen and Seymour J. KLebanoff \\ From the Department of Medicine, University of Washington School of \\ Medicine, Seattle, Washington 98195
}

A в S T R A C T The role of superoxide anion- and myeloperoxidase-dependent reactions in the light emission by phagocytosing polymorphonuclear leukocytes has been investigated using leukocytes that lack myeloperoxidase, inhibitors (azide, superoxide dismutase), and model systems. Our earlier finding that oxygen consumption, glucose $\mathrm{C}-1$ oxidation, and formate oxidation are greater in polymorphonuclear leukocytes that lack myeloperoxidase than in normal cells during phagocytosis has been confirmed with leukocytes from two newly described myeloperoxidase-deficient siblings. Although the maximal rate of superoxide anion production by myeloperoxidase-deficient leukocytes is not significantly different from that of normal cells, superoxide production falls off less rapidly with time so that with prolonged incubation, it is greater in myeloperoxidase-deficient than in normal cells. Chemiluminescence by myeloperoxidasedeficient leukocytes during the early postphagocytic period however is decreased. Light emission by normal leukocytes is strongly inhibited by both superoxide dismutase and azide, whereas that of myeloperoxidasedeficient leukocytes, while still strongly inhibited by superoxide dismutase is considerably less sensitive to azide. Zymosan, the phagocytic particle employed in the intact cell system, considerably increased the chemiluminescence of a cell-free superoxide- $\mathrm{H}_{2} \mathrm{O}_{2}$ generating system (xanthine-xanthine oxidase) and a system containing myeloperoxidase, $\mathrm{H}_{2} \mathrm{O}_{2}$, and chloride. Light emission by the xanthine oxidase model system is strongly inhibited by superoxide dismutase and is not inhibited by azide, whereas the myeloperoxidase-dependent model system is strongly inhibited by azide but only slightly inhibited by superoxide dismutase. These findings suggest that light emission by phagocytosing polymorphonuclear leukocytes

Dr. Rosen is the recipient of Postdoctoral Research Fellowship CA05225 from the National Cancer Institute, Department of Health, Education, and Welfare.

Received for publication 8 December 1975 and in revised form 16 February 1976. is dependent on both myeloperoxidase-catalyzed reactions and the superoxide anion, and involves in part the excitation of the ingested particle. These studies are discussed in relation to the role of the superoxide anion and chemiluminescence in the microbicidal activity of the polymorphonuclear leukocyte.

\section{INTRODUCTION}

There has been recent interest in the role of the superoxide anion $\left(\mathrm{O}_{2}^{-}\right)$, hydroxyl radicals $(\mathrm{OH} \cdot)$, and singlet oxygen $\left({ }^{1} \mathrm{O}_{2}\right)$ in the microbicidal activity of the polymorphonuclear leukocyte $(\mathrm{PMN}) .^{1}$ Microorganisms ingested by PMNs are exposed to a variety of antimicrobial systems (1). The partial inhibition of this antimicrobial activity under an atmosphere of nitrogen suggests that some of these systems require oxygen. Among the oxygen-dependent antimicrobial systems are those that require the granular enzyme myeloperoxidase (MPO). The bactericidal activity of MPO-deficient PMNs is characterized by a lag period after which death of the organism is observed (2-4). The defect in microbicidal activity during the early postphagocytic period is pronounced and suggests a requirement for MPO for optimal killing by normal PMNs. Myeloperoxidase, $\mathrm{H}_{2} \mathrm{O}_{2}$, and a halide form a potent antimicrobial system effective against bacteria, fungi, viruses, and mycoplasma. The bactericidal activity of MPO-deficient leukocytes also indicates the presence in these and presumably also in normal cells of microbicidal systems that are independent of MPO. These systems develop slowly but are ultimately effective. The staphylocidal activity of MPO-deficient PMNs, like that of normal cells, is partially inhibited by hypoxia (5) indicating that the MPO-independent antimicrobial systems are in part dependent on oxygen. These may include $\mathrm{H}_{2} \mathrm{O}_{2}$ (acting nonenzymatically or in conjunction with an enzyme

${ }^{1}$ Abbreviations used in this paper: BSS, balanced salt solution; CGD, chronic granulomatous disease; MPO, myeloperoxidase; PMN, polymorphonuclear leukocyte. 
other than MPO), superoxide anion, hydroxyl radicals, or electronically excited substances such as singlet molecular oxygen. The oxygen independent, antimicrobial systems include an acid $\mathrm{pH}$, lysozyme, lactoferrin, and granular cationic proteins (1).

The superoxide anion is formed either by the univalent reduction of oxygen or by the univalent oxidation of $\mathrm{H}_{2} \mathrm{O}_{2}(6)$. It is a highly reactive radical which can act both as an oxidant or as a reductant. When it functions as a reductant, as in the reduction of ferricytochrome $c$ or nitroblue tetrazolium, the superoxide anion is oxidized to oxygen. When it acts as an oxidant, as in the oxidation of epinephrine, the superoxide anion is reduced to $\mathrm{H}_{2} \mathrm{O}_{2}$. When two molecules interact, one is oxidized and the other reduced as follows:

$$
\mathrm{O}_{2}^{-}+\mathrm{O}_{2}^{-}+2 \mathrm{H}^{+} \rightarrow \mathrm{O}_{2}+\mathrm{H}_{2} \mathrm{O}_{2}
$$

This dismutation reaction occurs spontaneously and is also catalyzed by the enzyme superoxide dismutase. The growth of certain organisms is inhibited by $\mathrm{O}_{2}^{-}$, and this inhibition is related to the content and distribution of microbial superoxide dismutase $(7,8)$. This, together with the demonstration of $\mathrm{O}_{2}^{-}$formation by PMNs during phagocytosis (9-12) suggests its involvement in the microbicidal activity of the cell.

Hydroxyl radicals are formed by the interaction of $\mathrm{O}_{2}^{-}$ and $\mathrm{H}_{2} \mathrm{O}_{2}$ as follows :

$$
\mathrm{O}_{2}^{-}+\mathrm{H}_{2} \mathrm{O}_{2} \rightarrow \mathrm{OH} \cdot+\mathrm{OH}^{-}+\mathrm{O}_{2}
$$

The involvement of hydroxyl radicals in the microbicidal activity of the PMN has been proposed based on the inhibition of microbicidal activity by both catalase and superoxide dismutase and by scavengers of hydroxyl radicals such as mannitol and benzoate (12).

Chemiluminescence is the emission of light during the course of a chemical reaction. It implies the presence of energy-rich molecular states in which electrons occupy orbitals of higher than ground state energy. This excess energy can be dissipated by thermal decay, by light emission, or by increased chemical reactivity. That electronically excited substances are formed by PMNs during phagocytosis is indicated by the emission of light (13). Possible sources of the light emission are the relaxation of singlet molecular oxygen or excited substances dependent on singlet oxygen for their formation. In addition, excited substances may be formed by mechanisms that do not involve singlet oxygen. Ground state triplet oxygen is a biradical in which the spins of the two valence electrons of lowest energy are in the same direction, i.e., unpaired. Singlet molecular oxygen is formed when an absorption of energy shifts a valence electron to an orbital of higher energy with an inversion of spin (14). Singlet oxygen involvement in the microbicidal activity of the PMN has been proposed based on its suggested role in the toxicity due to dye-sensitized photo-oxygenation (photodynamic action) (15) and on the resistance of organisms rich in carotenoid pigments (which are potent single oxygen scavengers) to the microbicidal activity of PMNs (16).

Investigation of the role of oxygen-dependent but MPO-independent antimicrobial systems is facilitated by the use of PMNs that lack MPO. In this study, several parameters of the respiratory burst (oxygen consumption, $\left[1{ }^{14} \mathrm{C}\right]$ glucose oxidation, formate oxidation, superoxide anion formation, chemiluminescence) were investigated in the leukocytes of patients with hereditary MPO deficiency. The origin of the chemiluminescence of normal and MPO-deficient leukocytes was studied through the use of inhibitors (azide, superoxide dismutase) and model systems (xanthine + xanthine oxidase; MPO + $\mathrm{H}_{2} \mathrm{O}_{2}+$ chloride), and the results have been discussed in relation to the role of superoxide and light emission in the microbicidal activity of the cell.

\section{METHODS}

Special reagents. Zymosan obtained either from Nutritional Biochemicals Corporation, Cleveland, Ohio or from ICN Pharmaceuticals, Inc., Cleveland, Ohio, was suspended in water to a concentration of $10 \mathrm{mg} / \mathrm{ml}$ by homogenization at $4^{\circ} \mathrm{C}$ with a Potter-Elvehjem homogenizer. Where indicated zymosan was preopsonized by incubation for $20 \mathrm{~min}$ at $37^{\circ} \mathrm{C}$ with serum, followed by removal of unattached serum components by washing two times with water. $\mathrm{AB}$ serum stored at $-70^{\circ} \mathrm{C}$ was used. Ferricytochrome $c$ (horse heart, type VI) was obtained from Sigma Chemical Co., St. Louis, Mo., superoxide dismutase (bovine erythrocyte, $3,000+\mathrm{U} / \mathrm{mg}$ ) was from Truett Laboratories, Dallas, Texas and xanthine oxidase (bovine milk $10 \mathrm{mg} / \mathrm{ml}$ suspended in $2.0 \mathrm{M}$ ammonium sulfate, $0.01 \mathrm{M}$ EDTA) and catalase (beef liver $6.7 \mathrm{mg} / \mathrm{ml}, 62,900 \mathrm{U} / \mathrm{mg}$ ) were from Worthington Biochemical Corp., Freehold, N. J. Catalase was dialyzed against at least 1,000 vol of water before use. MPO was prepared from canine granulocytes by the method of Agner (17) to the end of step 6, and peroxidase activity was determined on the day of each experiment by the odianisidine method (18). $1 \mathrm{U}$ is that amount of enzyme decomposing $1 \mu \mathrm{mol}$ of $\mathrm{H}_{2} \mathrm{O}_{2} / \mathrm{min}$ at $25^{\circ} \mathrm{C}$. Catalase, MPO, and xanthine oxidase were heated at $100^{\circ} \mathrm{C}$ for $15 \mathrm{~min}$ and superoxide dismutase was heated at $120^{\circ} \mathrm{C}$ for $20 \mathrm{~min}$ where indicated. Balanced salt solution (BSS) contained sodium chloride $0.128 \mathrm{M}$, potassium chloride $12 \mathrm{mM}$, calcium chloride $1 \mathrm{mM}$, magnesium chloride $2 \mathrm{mM}$, phosphate buffer $\mathrm{pH} 7.44 \mathrm{mM}$, and glucose $2 \mathrm{mM}$. Staphylococcus aureus $502 \mathrm{~A}$ and Escherichia coli ATCC no. 11775 were maintained on blood agar plates and grown overnight in trypticase soy broth. The organisms were washed two times, suspended in water to the required optical density and heated at $100^{\circ} \mathrm{C}$ for $20 \mathrm{~min}$ just before use.

Preparation of leukocytes. Blood was collected from healthy adults, from three patients with MPO deficiency, from three male patients with chronic granulomatous disease (CGD) and from the mother of two of these patients. The patients with MPO deficiency consisted of one male patient (C. B.) previously studied extensively (2-4) and two siblings, one man (B. F.) age 16 and one woman (J. F.) age 19, not previously described. The latter patients presented with acne vulgaris. MPO deficiency was 
indicated by the absence of MPO from neutrophils and monocytes on histochemical examination (eosinophils were peroxidase-positive), low peroxidase activity in extracts of isolated granulocytes (normal, 2.34 $\pm 0.17 \mathrm{U} / 5 \times 10^{7} \mathrm{PMNs}$, $n=27$; B. F., $0.08 \mathrm{U} / 5 \times 10^{7} \mathrm{PMNs}, n=1 ;$ J. F., 0.07 $\mathrm{U} / 5 \times 10^{7}$ PMNs, $n=2$ ) and by phagocytosis-induced iodination which was $6.6 \pm 0.1(\mathrm{~J} . \mathrm{F} ., n=5)$ and $16.5 \pm 1.1$ (B. F., $n=2$ ) percent of normal. The blood was drawn in heparin $(20 \mathrm{U} / \mathrm{ml})$, and the leukocytes were isolated by dextran sedimentation and hypotonic lysis of erythrocytes. The leukocytes, which contained $65-95 \%$ PMNs, were suspended in BSS at a concentration of $1 \times 10^{7} \mathrm{PMNs} / \mathrm{ml}$ and stored on ice for periods of up to $3 \mathrm{~h}$ before use.

Measurement of the superoxide anion. The generation of $\mathrm{O}_{2}^{-}$by $\mathrm{PMNs}$ was estimated by a modification of the method of Babior et al. (9). In this assay, the superoxide dismutase-inhibitable reduction of ferricytochrome $c$ by intact PMNs is employed as a measure of superoxide formation. This method measures only that superoxide which reacts with cytochrome $c$ under the assay conditions and thus presumably only a portion of the superoxide formed.

In the measurement of superoxide by intact cells, the standard reaction mixture contained $0.1 \mathrm{mM}$ ferricytochrome c, $5 \%$ serum, $1 \mathrm{mg}$ zymosan $\left(80 \times 10^{6}\right.$ particles $) / \mathrm{ml}$ and $2.5 \times 10^{5} \mathrm{PMNs} / \mathrm{ml}$ in BSS. Paired reactions with and without added superoxide dismutase $(12 \mu \mathrm{g} / \mathrm{ml})$ were employed, and zymosan was deleted for resting values. The final volume was either 4 or $8 \mathrm{ml}$. Variations from this standard reaction mixture are indicated in the text and legends. All the components except zymosan were added to siliconized glass scintillation vials $(25 \times 43 \mathrm{~mm})$ and preincubated at $37^{\circ} \mathrm{C}$ in a water bath oscillating 80 times/ min for 5-10 min. Zymosan was added at zero time, and $0.9-\mathrm{ml}$ samples were transferred immediately (zero time) and at intervals to iced $10 \times 75 \mathrm{~mm}$ test tubes. At the completion of the experiment, the tubes were centrifuged at $4^{\circ} \mathrm{C} 1,500 \mathrm{~g}$ for $5 \mathrm{~min}$, and the difference spectra of the supernatant solutions were determined between 540 and $560 \mathrm{~nm}$ using $0.1 \mathrm{mM}$ ferricytochrome $c$ as the blank. Spectrophotometric measurements were made with a Cary M15 spectrophotometer (Applied Physics Corp., Monrovia, Calif.). Nanomoles of cytochrome $c$ reduced were determined from the increase in the absorbance at the maximum between 545 and $550 \mathrm{~nm}$ using $\mathrm{E}_{\Delta}=21.0 \mathrm{~cm}^{-1} \mathrm{mM}^{-1}$ (19). A regression line was fitted to the data points of the linear portion of the kinetic curve, and the maximum rate of cytochrome $c$ reduction was determined from the slope of the line. Superoxide-dependent cytochrome $c$ reduction, i.e., the difference in the rate of cytochrome $c$ reduction between parallel samples with and without added superoxide dismutase, was used as a measure of superoxide anion formation. The results are expressed as nmol/10 $\mathrm{PMNs}$ / $\min$.

Superoxide production by the xanthine oxidase system was determined before each experiment. Xanthine oxidase $(0.01 \mathrm{mg} / \mathrm{ml})$ was added to a reaction mixture containing $10 \mathrm{mM}$ phosphate buffer $\mathrm{pH} 7.4,0.1 \mathrm{mM}$ xanthine, $0.1 \mathrm{mM}$ EDTA, and $0.1 \mathrm{mM}$ ferricytochrome $c$ in a final volume of $1 \mathrm{ml}$. The rate of cytochrome $c$ reduction was measured spectrophotometrically for $2 \mathrm{~min}$ at $25^{\circ} \mathrm{C}$ by the increase in absorbance at $547.5 \mathrm{~nm}$ and converted to nanomoles $/ \mathrm{min}$. The difference between this rate and the one determined in the presence of superoxide dismutase $(9 \mu \mathrm{g} / \mathrm{ml})$ was used for the calculation of superoxide production.

Measurements of chemiluminescence. All manipulations were performed under red actinic light. Reaction vessels consisted of cylindrical polyethylene vials (15 $\mathrm{mm}$ diameter) that had been stored in the dark for at least $20 \mathrm{~h}$ before use. Measurements were made at ambient temperature in a Beckman LS-100C liquid scintillation counter (Beckman Instruments, Inc., Fullerton, Calif.) operating in the out of coincidence mode with a single photomultiplier tube activated and a 0 to $\alpha$ window. Under these conditions the activity for empty vials ranged between 2,000 and 4,000 cpm. The results are expressed as counts per minute above background.

For the measurement of chemiluminescence by intact cells the standard reaction mixture contained $2 \times 10^{\circ}$ PMNs, 5$10 \%$ serum, $1 \mathrm{mg}$ zymosan, and either BSS or modified Hanks solution (20) to a final volume of $1.0 \mathrm{ml}$. Zymosan was omitted for the determination of resting values. Variations are indicated in the text and legends. The reaction was initiated by the addition of $\mathrm{PMNs}$, and the vials were incubated in a $37^{\circ} \mathrm{C}$ water bath oscillating at 80 cycles $/ \mathrm{min}$. At intervals the vials were blotted dry, placed in the counter for a 30 -s chemiluminescence measurement and then returned to the water bath. The vials were absent from the water bath for less than $1 \mathrm{~min}$ in every 10 . In general, measurements were continued for $60 \mathrm{~min}$.

For the measurement of chemiluminescence by the model enzyme systems, the components of the reaction (see legends), with the exception of the enzyme, were added to the vials, and chemiluminescence was measured for a 2-min period (background). The reaction was initiated by the addition of enzyme, and the vials were returned promptly to the scintillation counter for a second 2 min count. The results are expressed as counts per minute above background.

Other procedures. Oxygen consumption was determined manometrically (5) and $\left[1-{ }^{14} \mathrm{C}\right]$ glucose and $\left[{ }^{14} \mathrm{C}\right]$ formate oxidation were assessed by the collection of ${ }^{14} \mathrm{CO}_{2}$ in alkali and the measurement of radioactivity in a liquid scintillation counter (21). For the measurement of phagocytosis the reaction mixture was identical to that used for PMN chemiluminescence. The reaction was stopped after $15 \mathrm{~min}$ of incubation by immersion of the vials in ice. Cover slip smears were stained, and the average number of particles per neutrophil and the percent of neutrophils that contained ingested particles determined. Incubations were performed in quadruplicate, and at least 100 cells were counted per determination. Kinetic studies indicated that phagocytosis was still progressing at $15 \mathrm{~min}$. Cell viability was determined under conditions of the superoxide anion assay by combining samples of the reaction mixture with an equal volume of $0.16 \%$ trypan blue in normal saline containing $2 \mathrm{mM}$ glucose and determining the total number of cells and the percentage of stained (nonviable) cells in a hemocytometer.

Statistical analyses. Mean \pm standard error was employed unless otherwise indicated. Statistical differences were determined using Student's $t$ test (NS, $P>0.05)$. Instances in which experimental values were compared with paired controls are indicated in the text (paired analysis); otherwise comparisons were of aggregate mean values. Linear regression lines were fitted to data points by the method of least squares.

\section{RESULTS}

Previous studies in our laboratory had suggested that the phagocytosis induced-metabolic burst by the leukocytes of a patient with hereditary MPO deficiency (C. B.) was greater than that of normal leukocytes. 
Oxygen consumption $(5),\left[1-{ }^{14} \mathrm{C}\right]$ glucose oxidation (21), and formate oxidation (21) by the MPO-deficient leukocytes was high. Table I confirms the increase in the activity of these parameters in MPO deficiency, using the leukocytes of the two new patients with this condition (J. F., B. F.).

Superoxide anion formation. In the technique employed here for the measurement of $\mathrm{O}_{2}^{-}$formation by PMNs, superoxide dismutase-inhibitable cytochrome $c$ reduction was determined at short intervals after the addition of particles and the maximal rate of $\mathrm{O}_{2}^{-}$formation calculated. The basis for this measurement is shown in Figs. 1 and 2. Fig. 1 demonstrates the reduction of cytochrome $c$ by PMNs as a function of time, both in the presence (phagocytosis) and absence (resting) of zymosan and in the presence and absence of superoxide dismutase. The rate of cytochrome $c$ reduction by resting PMNs is low and nearly constant and is decreased approximately $50 \%$ by the addition of superoxide dismutase. When zymosan is added, there is a marked increase in the rate of cytochrome $c$ reduction after a lag period of approximately $5 \mathrm{~min}$. The rate of cytochrome $c$ reduction reaches a maximum at about $8 \mathrm{~min}$, continues essentially unchanged until approximately $20 \mathrm{~min}$ of incu-

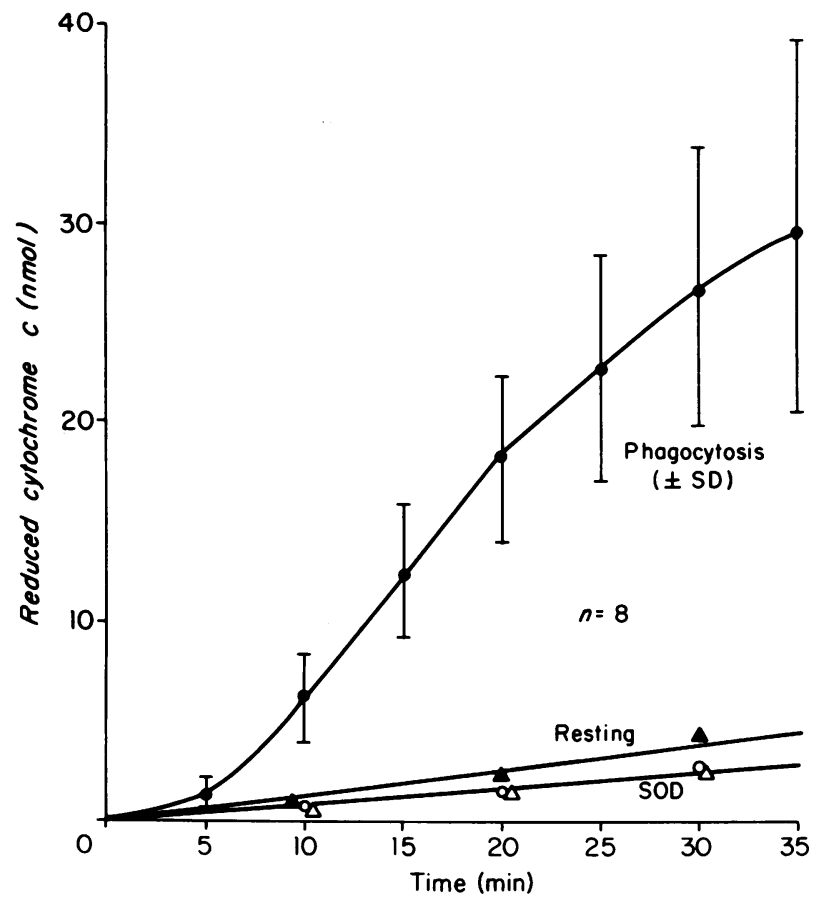

Figure 1 Cytochrome $c$ reduction by normal PMNs. The components of the reaction mixture were as described under Methods. Cytochrome $c$ reduction by resting $\mathrm{PMNs}$ in the presence $(\Delta)$ and absence $(\boldsymbol{\Delta})$ of superoxide dismutase and phagocytosing PMNs in the presence (O) and absence (๑) of superoxide dismutase is shown. Where not shown in the figure, standard deviation about the mean was less than $1.8 \mathrm{nmol}$.

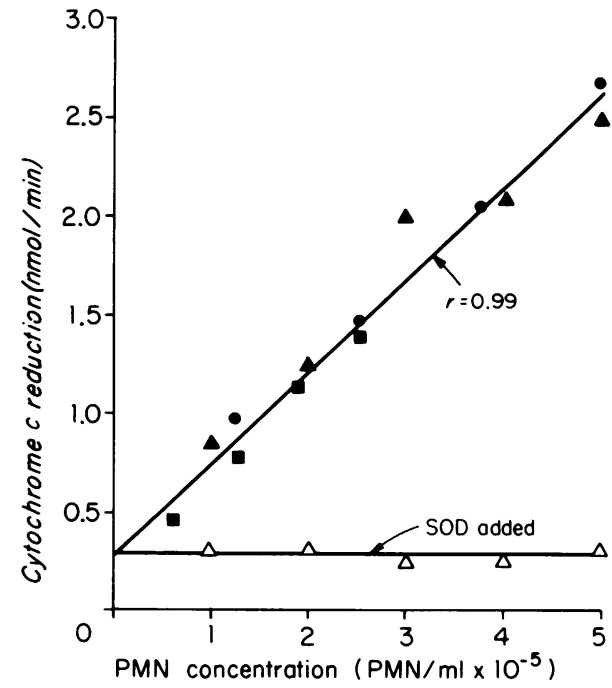

Figure 2 Effect of PMN concentration. The maximal rate of cytochrome $c$ reduction by phagocytosing PMNs in the presence $(\Delta)$ and absence $(\boldsymbol{\theta}, \Delta, \square)$ of superoxide dismutase is shown as a function of PMN concentration. Results of three experiments (maximal rate- $=7.8, \Delta=$ $3.9, \quad=7.3 \mathrm{nmol} / 10^{\circ} \mathrm{PMNs} / \mathrm{min}$ ) were normalized to 5.0 $\mathrm{nmol} / 10^{6} \mathrm{PMNs} / \mathrm{min}$, to emphasize the linear dependence on PMN concentration. The coefficients of linear correlation are each $r>0.97$ and $r=0.99$ overall.

bation and then decreases. More than $90 \%$ of the zymosan-stimulated response is inhibited in the presence of superoxide dismutase. The slope of a line fitted to data points between 10 and $20 \mathrm{~min}$ was used as the estimate of maximal cytochrome $c$ reduction. Superoxide anion production is taken as the difference between slopes for samples differing only by the presence or absence of superoxide dismutase. When the superoxide anion production is measured as a function of PMN concentration, the relationship is linear for concentrations of cells ranging from 0 to $5 \times 10^{5} \mathrm{PMNs} / \mathrm{ml}$ (Fig. 2). $2.5 \times 10^{5}$ $\mathrm{PMNs} / \mathrm{ml}$ were routinely employed, and the results were expressed as nanomoles of superoxide per $10^{\circ}$ PMNs per minute.

Table II indicates the maximal rate of superoxide production by the leukocytes of 11 normal subjects, two male patients with CGD, one CGD carrier, and three patients with hereditary MPO deficiency. In normal subjects phagocytosis of zymosan particles increased superoxide production from 0.3 to $4.7 \mathrm{nmol} / 10^{6} \mathrm{PMNs} /$ min, i.e., 16-fold. As previously reported (22), leukocytes from patients with CGD produced little or no $\mathrm{O}_{2}^{-}$ during phagocytosis, and intermediate levels of $\mathrm{O}_{2}^{-}$were generated by the PMNs of a female carrier of CGD. The PMNs of the patients with hereditary MPO deficiency generated $\mathrm{O}_{2}^{-}$at a normal maximal rate during phagocytosis (Table II). An increase in superoxide production by the MPO-deficient cells however was 
TABLE I

Oxygen Consumption, Glucose C-1 Oxidation, and Formate Oxidation by MPO-Deficient Leukocytes

\begin{tabular}{|c|c|c|c|c|c|c|}
\hline \multirow[b]{2}{*}{ Measurement } & \multicolumn{2}{|c|}{ Normal } & \multicolumn{2}{|c|}{ J. F. } & \multicolumn{2}{|c|}{ B. F. } \\
\hline & Resting & Phagocytosis & Resting & Phagocytosis & Resting & Phagocytosis \\
\hline Oxygen consumption* & & $224 \pm 21$ & & $584 \pm 21$ & & $624 \pm 40$ \\
\hline Glucose $\mathrm{C}-1$ oxidation $\ddagger$ & $6 \pm 2(4)$ & $195 \pm 17$ & $9 \pm 3(3)$ & $513 \pm 20(3)$ & $6 \pm 3(2)$ & $414 \pm 79$ \\
\hline Formate oxidation $\ddagger$ & $6 \pm 0.5(3)$ & $29 \pm 1(3)$ & $12 \pm 5(2)$ & $53 \pm 7(2)$ & $8 \pm 1(2)$ & $74 \pm 10(2)$ \\
\hline
\end{tabular}

Mean \pm SE of $(n)$ experiments with each $n$ the mean of duplicate tubes.

Significance of difference between normal and combined MPO-deficient data (phagocytosis): oxygen consumption, $P<0.001$; glucose C-1 oxidation, $P<0.001$; formate oxidation, $P<0.02$.

${ }^{*} \mathrm{nmol} / 10^{7} \mathrm{PMN} / 20 \mathrm{~min}$.

$\ddagger \mathrm{nmol} / 10^{7} \mathrm{PMN} / \mathrm{h}$.

clearly evident with prolonged incubation (Fig. 3). A1though the maximal rates of superoxide production are comparable in this figure (normal 4.1 \pm 1.2 , MPO-deficient $4.8 \pm 0.9 \mathrm{nmol} / 10^{\circ} \mathrm{PMNs} / \mathrm{min}$ ), superoxide production by normal cells fell more rapidly than did that of MPO-deficient cells so that between 90 and $120 \mathrm{~min}$ the rate of production by normal cells had fallen essentially to zero $\left(0.1 \pm 0.1 \mathrm{nmol} / 10^{\circ} \mathrm{PMNs} / \mathrm{min}\right)$, whereas that of MPO-deficient cells remained at $40 \%$ of the maximal rate $\left(2.0 \pm 0.2 \mathrm{nmol} / 10^{6} \mathrm{PMNs} / \mathrm{min}\right)$. The difference was significant $(P<0.002)$. Using trypan blue exclusion, no difference in cell viability between normal and MPO-deficient leukocytes was detected under the conditions employed in Fig. 3.

Chemiluminescence-intact cells. Fig. 4 demonstrates the chemiluminescent response to phagocytosis of normal, CGD, and MPO-deficient PMNs. Light emission by normal cells increased markedly after particle ingestion and then fell. As previously reported by others $(13,23)$, chemiluminescence was greatly decreased in the absence of phagocytosis or when the leukocytes of patients with CGD were employed. Intermediate levels were detected from the leukocytes of the mother of two male children with CGD, as would be expected from the $\mathrm{X}$-linked nature of the disease in these patients. Chemiluminescence was also decreased during the early post- phagocytic period when the leukocytes of three patients with hereditary MPO deficiency were employed. At 10 min after the addition of particles, chemiluminescence by MPO-deficient leukocytes was $43 \%$ of that of normal cells. With continued incubation however, light emission by normal cells fell to a level below that of MPOdeficient cells. The mean values at each time period are shown in Fig. 4, and an analysis of individual patient populations and comparison with the norm are shown in Table III.

The effect of azide and superoxide dismutase on light emision by normal and MPO-deficient leukocytes is shown in Fig. 5. At 10 min after the addition of particles to normal PMNs, $1 \mathrm{mM}$ azide produced at $63 \pm 2 \%$ inhibition $(n=15, P<0.001)$ of the phagocytosis-induced increment in light emission and $0.01 \mathrm{mM}$ azide caused a $50 \pm 2 \%$ inhibition $(n=11, P<0.001)$. When MPO-deficient leukocytes were employed, the inhibition by azide was considerably reduced. At $10 \mathrm{~min}, 1 \mathrm{mM}$ azide decreased chemiluminescence $29 \pm 6 \% \quad(n=6, P<$ 0.01 ), whereas at a concentration of $0.01 \mathrm{mM}$, azide inhibition was $23 \pm 4 \%(n=5, \mathrm{P}<0.002)$. Chemiluminescence by normal PMNs in the presence of azide $(1 \mathrm{mM})$ was not significantly different than that of MPO-deficient leukocytes in the absence of azide. When normal cells were employed, a $75 \pm 2 \%$ inhibition $(n=16, P<$

TABLE II

Superoxide Anion Production by Normal, CGD and MPO-Deficient Leukocytes

\begin{tabular}{lllcc}
\hline \multirow{2}{*}{\multicolumn{1}{c}{ Patients }} & \multicolumn{4}{c}{ Superoxide anion production, nmol/106 $P M N$ per min } \\
\cline { 2 - 5 } & Resting & $P^{*}$ & Phagocytosis & $P$ \\
\hline Normal (11) $\ddagger$ & $0.3 \pm 0.1(8) \S$ & & $4.7 \pm 0.4(14)$ & \\
CGD (2) & $0.0(1)$ & NS & $-0.1 \pm 0.04(3)$ & $<0.001$ \\
CGD heterozygote (1) & $0.0 \pm 0.0(2)$ & NS & $3.0 \pm 0.5(4)$ & 0.05 \\
MPO deficiency (3) & $0.3 \pm 0.1(6)$ & NS & $4.9 \pm 0.4(9)$ & NS \\
\hline
\end{tabular}

* Significance level of difference from normal.

$\ddagger$ Number of patients.

$\S$ Mean \pm SE of $(n)$ experiments. 
TABLE III

Analysis of PMN Chemiluminescence

\begin{tabular}{|c|c|c|c|c|c|c|}
\hline \multirow[b]{3}{*}{ Patients } & \multicolumn{6}{|c|}{ Chemiluminescence } \\
\hline & \multicolumn{3}{|c|}{$10 \mathrm{~min}$} & \multicolumn{3}{|c|}{$90 \mathrm{~min}$} \\
\hline & $\operatorname{cpm} \pm \mathrm{SE}(n)$ & $\begin{array}{c}\% \text { of } \\
\text { normal }\end{array}$ & $P^{*}$ & $\operatorname{cpm} \pm \mathrm{SE}(n)$ & $\begin{array}{c}\% \text { of } \\
\text { normal }\end{array}$ & $P$ \\
\hline \multicolumn{7}{|l|}{ Phagocytosis } \\
\hline Normal & $70,000 \pm 3,600(21)$ & & & $4,600 \pm 1,500$ & & \\
\hline MPO-deficient & $30,100 \pm 3,800(8)$ & 43 & $<0.001$ & $13,300 \pm 1,800$ & 289 & $<0.05$ \\
\hline CGD & $3,400 \pm 700$ & 5 & $<0.001$ & & & \\
\hline \multicolumn{7}{|l|}{ Resting } \\
\hline Normal & $900 \pm 300(19)$ & & & & & \\
\hline
\end{tabular}

* Significance level of difference from normal.

0.001 ) of chemiluminescence at $10 \mathrm{~min}$ was produced by superoxide dismutase at a concentration of $94 \mu \mathrm{g} / \mathrm{ml}$ and a $55 \pm 3 \%$ inhibition $(n=8, P<0.001)$ at a concentration of $9.4 \mu \mathrm{g} / \mathrm{ml}$. This effect of superoxide dismutase was abolished by heating the enzyme at $120^{\circ} \mathrm{C}$ for $20 \mathrm{~min}$. When MPO-deficient leukocytes were employed, superoxide dismutase produced a $79 \pm 4 \%$ inhibition $(n=$ $6, P<0.001)$ at a concentration of $94 \mu \mathrm{g} / \mathrm{ml}$ and a $67 \pm$ $4 \%$ inhibition $(n=5, P<0.001)$ at a concentration of $9.4 \mu \mathrm{g} / \mathrm{ml}$. When azide $(1 \mathrm{mM})$ and superoxide dismutase $(94 \mu \mathrm{g} / \mathrm{ml})$ were combined, a $92 \pm 1 \%$ inhibition $(n=8, P<0.001)$ of chemiluminescence was observed with normal cells, and an $86 \pm 1 \%$ inhibition $(n=5, P<$ $0.001)$ was observed with MPO-deficient cells. The azide + superoxide dismutase inhibition of MPO-deficient cells was not significantly different from the inhibition by superoxide dismutase alone. Azide $(1 \mathrm{mM})$ and superoxide dismutase $(94 \mu \mathrm{g} / \mathrm{ml})$, either alone or in combination had no effect on phagocytosis under these experimental conditions.

Chemiluminescence-cell free systems. To explore possible sources of PMN chemiluminescence, two cell free chemiluminescent systems were investigated, one mediated by MPO and the other by xanthine oxidase.

Allen (24) observed light emission on the incubation of $\mathrm{MPO}, \mathrm{H}_{2} \mathrm{O}_{2}$, and chloride ions. When the $\mathrm{H}_{2} \mathrm{O}_{2}$ concentration was $25 \mathrm{mM}$ and the MPO concentration 0.03 $\mathrm{U} / \mathrm{ml},{ }^{2}$ chemiluminescence increased with an increase in chloride concentration to a maximum at $0.25 \mathrm{M}$ (24). The $\mathrm{pH}$ optimum was 5.0 (25). In the experiments reported here (Table IV), the $\mathrm{H}_{2} \mathrm{O}_{2}$ concentration was $0.1 \mathrm{mM}$, the MPO concentration $0.08 \mathrm{U} / \mathrm{ml}$, the chloride concentration $0.1 \mathrm{M}$, and the $\mathrm{pH}$ was 5.0. Under these conditions, low but significant chemiluminescence

\footnotetext{
${ }^{2}$ The unit employed in this study (25) is equal to the amount of enzyme required to produce an increase in absorbency of $0.001 / \mathrm{min}$ at $460 \mathrm{~nm}$. It has been converted to the unit employed here by multiplication by $2.655 \times 10^{-4}$.
}

(3,900 cpm above background, $P<0.001)$ was observed which was dependent on all three components of the system. Light emission was considerably increased by the addition of zymosan (unopsonized or preopsonized), $S$. aureus or $E$. coli to the reaction mixture. Deletion of MPO or $\mathrm{H}_{2} \mathrm{O}_{2}$ from the zymosan supplemented (complete) system markedly reduced chemiluminescence; however when chloride was omitted, considerable light emission was still evident. Chemiluminescence by the MPO- $\mathrm{H}_{2} \mathrm{O}_{2}$-chloride-zymosan system was inhibited by

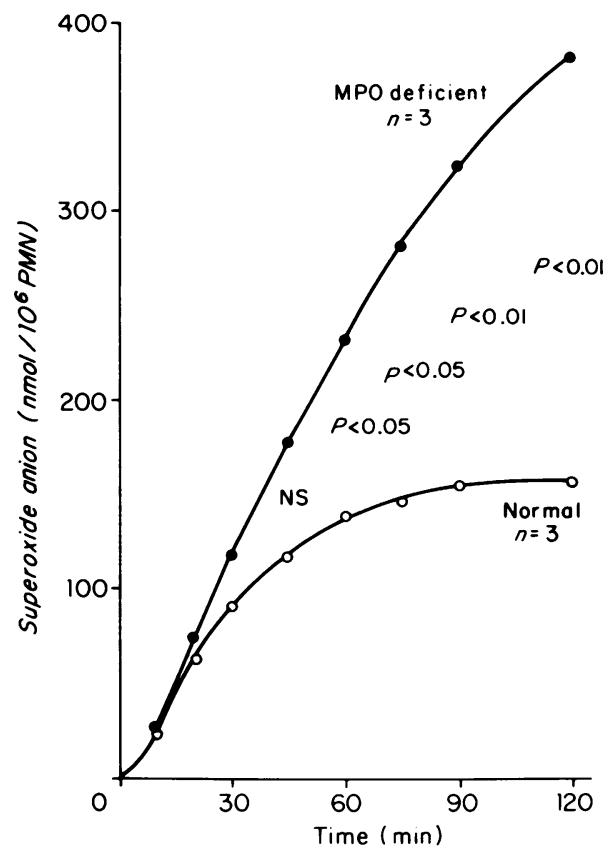

Figure 3 Kinetics of superoxide production by normal (O) and MPO-deficient (๑) cells. The conditions were as described in the Methods section except that the PMN concentration was decreased to $10^{5} / \mathrm{ml}$, and the length of incubation prolonged to $2 \mathrm{~h}$. The results are the mean of three experiments (J. F.-1; B. F.-1; C. B.-1; three different controls). Statistical significance at each time period was determined by paired analysis. 


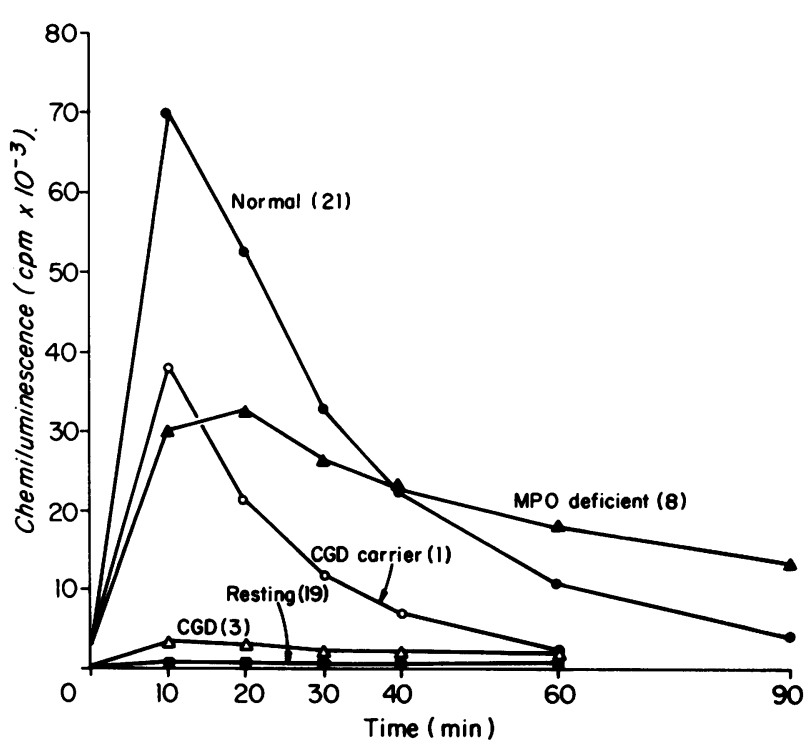

FIGURE 4 Chemiluminescence by $P M N$ s from 17 normal $(\bullet), 3 \mathrm{CGD}(\triangle), 1 \mathrm{CGD}$ carrier $(\mathrm{O})$ and $3 \mathrm{MPO}-$ deficient $(\Delta)$ individuals. The results are the mean of $(n)$ determinations. There was no significant difference in resting PMN chemiluminescence between normal ( $\square$ ) and patient PMNs.

$5 \%$ serum and $1 \mathrm{mM}$ azide. Superoxide dismutase at a concentration of $94 \mu \mathrm{g} / \mathrm{ml}$ had a small but significant $(P<0.05)$ inhibitory effect on light emission.

Oxidation of xanthine by xanthine oxidase in phosphate buffer, $\mathrm{pH} 7.4$ containing $0.1 \mathrm{mM}$ EDTA produced an emission of light $(5,000 \mathrm{cpm}$ above background, $P<0.002)$ under the conditions employed in Table V. Chemiluminescence by this system was increased by zymosan $(P<0.01)$ and by serum $(P<$ 0.002 ), and when the two were combined (complete system), an additive effect was observed. Light emission by the complete system increased for the first 2-3 min of measurement and then declined (Fig. 6). This decline in chemiluminescence correlated with the termination of superoxide anion formation as measured by ferricytochrome $\mathrm{c}$ reduction (Fig. 6). The concentration of xanthine oxidase in Table $\mathrm{V}$ was adjusted so that the rate of $\mathrm{O}_{2}^{-}$generation $(9.7 \mathrm{nmol} / \mathrm{min}$.) was equivalent to that of $2 \times 10^{6} \mathrm{PMNs} / \mathrm{ml}$ when mixed with zymosan and serum under the conditions employed in Table II. Light emission by the complete xanthine-xanthine oxidase-zymosan-serum system was nearly abolished by the deletion of either xanthine $(P<0.001)$ or xanthine oxidase $(P<0.001)$ or by the addition of $94 \mu \mathrm{g} / \mathrm{ml}$ native (but not heat-inactivated) superoxide dismutase $(P<$ 0.001 ) (Table V). Unheated catalase also was inhibitory $(P<0.001)$, although not to the same degree as was superoxide dismutase. An inhibition by both superoxide dismutase and catalase is compatible with the involve- ment of $\mathrm{OH}$ - in the light emission; of the three $\mathrm{OH}$. scavengers tested, benzoate $(10 \mathrm{mM})$ was without effect, and mannitol $(50 \mathrm{mM})$ and ethanol $(10 \mathrm{mM})$ had a small but significant (mannitol $P<0.02$; ethanol $P<$ 0.01 ) inhibitory effect on chemiluminescence. Azide at a final concentration of $1 \mathrm{mM}$ did not inhibit chemiluminescence; indeed, a small but significant $(P<0.02)$ stimulatory effect of azide on light emission by the xanthine oxidase system was observed.

\section{DISCUSSION}

MPO-deficient leukocytes are not defective in oxidative metabolism in contrast to the leukocytes of patients with CGD. Indeed, our earlier studies $(5,21)$ and those reported here suggest an increase in phagocytosis-induced oxygen consumption, glucose $\mathrm{C}-1$ oxidation, and formate oxidation by these cells. An additional parameter of the respiratory burst is superoxide anion generation, and the formation of this radical by MPO-deficient leukocytes, as measured by superoxide dismutase-inhibitable cytochrome $c$ reduction, is also greater than that of normal cells particularly on extended incubation with particles. This effect could not be accounted for by prolonged viability of the MPO-deficient cells as measured by trypan blue exclusion. Dye exclusion during the 2-h postphagocytic period however may not be a sensitive measure of damage to the granulocyte (26). MPO, in combination with $\mathrm{H}_{2} \mathrm{O}_{2}$ and a halide is toxic to $\mathrm{PMNs}$ as assessed by ${ }^{81} \mathrm{Cr}$ release (27), and the toxicity of this system may play a role in the more rapid decline in superoxide production by normal, as compared to MPOdeficient, PMNs.

In contrast to the other parameters of the respiratory burst, light emission by MPO-deficient leukocytes is de-

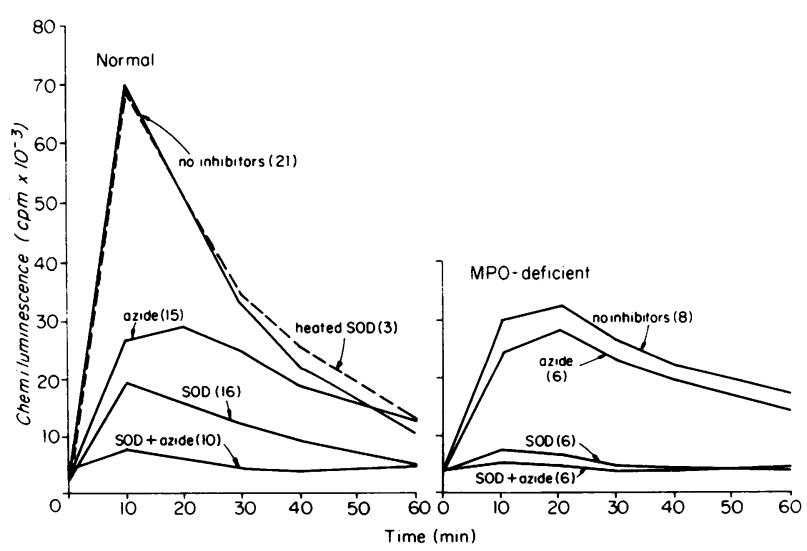

FIGURE 5 Effect of sodium azide and superoxide dismutase on chemiluminescence by normal and MPO-deficient PMNs. Conditions are as described in Fig. 4 with the additions as follows: azide $1 \mathrm{mM}$; superoxide dismutase $94 \mu \mathrm{g} / \mathrm{ml}$. The results are the means of the number of experiments shown in parenthesis. 
TABLE IV

Chemiluminescence by the MPO System

\begin{tabular}{lcc}
\hline \multicolumn{1}{c}{ Supplements } & $\begin{array}{c}\text { Chemiluminescence } \\
\text { CPM } \pm \text { SE }(n)\end{array}$ & $\begin{array}{c}\text { Significance } \\
P *\end{array}$ \\
\hline MPO System & $3,900 \pm 600(16)$ & \\
MPO omitted & $200 \pm 100(2)$ & $<0.05$ \\
$\mathrm{H}_{2} \mathrm{O}_{2}$ omitted & $500 \pm 300(5)$ & $<0.01$ \\
Chloride omitted & $600 \pm 50(4)$ & $<0.02$ \\
Zymosan added & $13,900 \pm 600(20)$ & $<0.001$ \\
S. aureus added & $6,800 \pm 200(4)$ & $<0.05$ \\
$E$. coli added & $12,400 \pm 400(4)$ & $<0.001$ \\
Complete system (MPO system + zymosan) & $13,900 \pm 600(20)$ & \\
MPO omitted & $200 \pm 40(6)$ & $<0.001$ \\
$\mathrm{H}_{2} \mathrm{O}_{2}$ omitted & $500 \pm 100(6)$ & $<0.001$ \\
Chloride omitted & $9,800 \pm 800(7)$ & $<0.002$ \\
Azide added & $800 \pm 200(4)$ & $<0.001$ \\
Serum added & $1,200 \pm 200(4)$ & $<0.001$ \\
SOD added & $11,000 \pm 500(4)$ & $<0.05$ \\
Zymosan replaced by preopsonized zymosan & $17,600 \pm 100(2)$ & $\mathrm{NS}$ \\
\hline
\end{tabular}

The MPO system consisted of $10 \mathrm{mM}$ sodium acetate buffer $\mathrm{pH} 5.0,0.08 \mathrm{U}$ MPO, $0.1 \mathrm{mM} \mathrm{H}_{2} \mathrm{O}_{2}, 0.1 \mathrm{M}$ sodium chloride in a total volume of $1.0 \mathrm{ml}$. The complete system contained in addition $1 \mathrm{mg}$ zymosan. Staphylococcus aureus $\mathrm{OD}_{510}=1.1$, Escherichia coli $\mathrm{OD}_{540}=1.1$, sodium azide, $1 \mathrm{mM}$, serum, $5 \%$, superoxide dismutase (SOD), $94 \mu \mathrm{g}$ and preopsonized zymosan, $1 \mathrm{mg}$ were added where indicated.

* Significance level of difference from MPO or complete system.

creased during the early postphagocytic period. This early depression of light emission parallels the microbicidal defect in these cells. The role of peroxidasecatalyzed reactions and the superoxide anion in the generation of excited states in the PMN was investigated further with the use of inhibitors (azide, superoxide dismutase) and either model systems or intact cells.

The incubation of $\mathrm{MPO}, \mathrm{H}_{2} \mathrm{O}_{2}$ and a halide results in light emission (24). Chemiluminescence is most pronounced with bromide as the halide with considerable light emission also present when chloride is used. Chemiluminescence in the presence of iodide is low and limited to a narrow range of iodide concentrations. We have confirmed the light emission by the $\mathrm{MPO}-\mathrm{H}_{2} \mathrm{O}_{2}-$ chloride system and have demonstrated a considerable increase in chemiluminescence on the addition of zymosan to the reaction mixture. Chemiluminescence by the $\mathrm{MPO}-\mathrm{H}_{2} \mathrm{O}_{2}$-chloride-zymosan system was largely abolished by $1 \mathrm{mM}$ azide at $\mathrm{pH} 5.0$, whereas superoxide dismutase had little effect.

When hypochlorite is added to an excess of $\mathrm{H}_{2} \mathrm{O}_{2}$, oxygen is released in an amount nearly equivalent to the amount of hypochlorite added. A weak red chemiluminescence accompanies this reaction, and the intermediate responsible for this emission is singlet oxygen $(28,29)$. The oxidation of chloride by $\mathrm{MPO}$ and $\mathrm{H}_{2} \mathrm{O}_{2}$ results in the formation of a highly reactive species which resembles hypochlorite in its chemical properties
$(30,31)$, and the hypochlorite formed in this way might be expected to react with excess $\mathrm{H}_{2} \mathrm{O}_{2}$ to form singlet oxygen. We have recently demonstrated the conversion of diphenylfuran to cis-dibenzoylethylene, a reaction specific for singlet oxygen (32), by $\mathrm{MPO}, \mathrm{H}_{2} \mathrm{O}_{2}$, and

TABLE V

Chemiluminescence by the Xanthine Oxidase System

\begin{tabular}{lr}
\hline \multicolumn{1}{c}{ Supplements } & $\begin{array}{c}\text { Chemiluminescence } \\
\text { cpm } \pm \text { SE }(n)\end{array}$ \\
\hline Xanthine oxidase system & $5,000 \pm 500(4)$ \\
Zymosan added & $9,100 \pm 700(4)$ \\
Serum added & $9,700 \pm 700(4)$ \\
Complete system & \\
(xanthine oxidase system + zymosan + serum) & $14,300 \pm 600(8)$ \\
Xanthine omitted & $1,600 \pm 400(4)$ \\
Xanthine oxidase omitted & $1,000 \pm 300(4)$ \\
SOD added & $1,400 \pm 200(5)$ \\
Heated SOD added & $18,800 \pm 200(4)$ \\
Catalase added & $8,700 \pm 400(6)$ \\
Heated catalase added & $15,600 \pm 200(3)$ \\
Benzoate added & $13,400 \pm 700(6)$ \\
Mannitol added & $11,600 \pm 400(4)$ \\
Ethanol added & $10,900 \pm 200(4)$ \\
Azide added & $17,400 \pm 800(7)$ \\
\hline
\end{tabular}

The xanthine oxidase system consisted of $10 \mathrm{mM}$ sodium phosphate buffer pH 7.4, 0.1 mM EDTA, 0.1 mM xanthine, and $0.1 \mathrm{mg}$ xanthine oxidase in a total volume of $1.0 \mathrm{ml}$. The complete system contained in addition $1 \mathrm{mg}$ zymosan and $5 \%$ serum. Superoxide dismutase (SOD), $94 \mu \mathrm{g}$, catalase, $6.7 \mu \mathrm{g}$, sodium benzoate, $10 \mathrm{mM}$, mannitol, $50 \mathrm{mM}$, ethanol, $10 \mathrm{mM}$, and sodium azide, $1 \mathrm{mM}$ were added where indicated. 


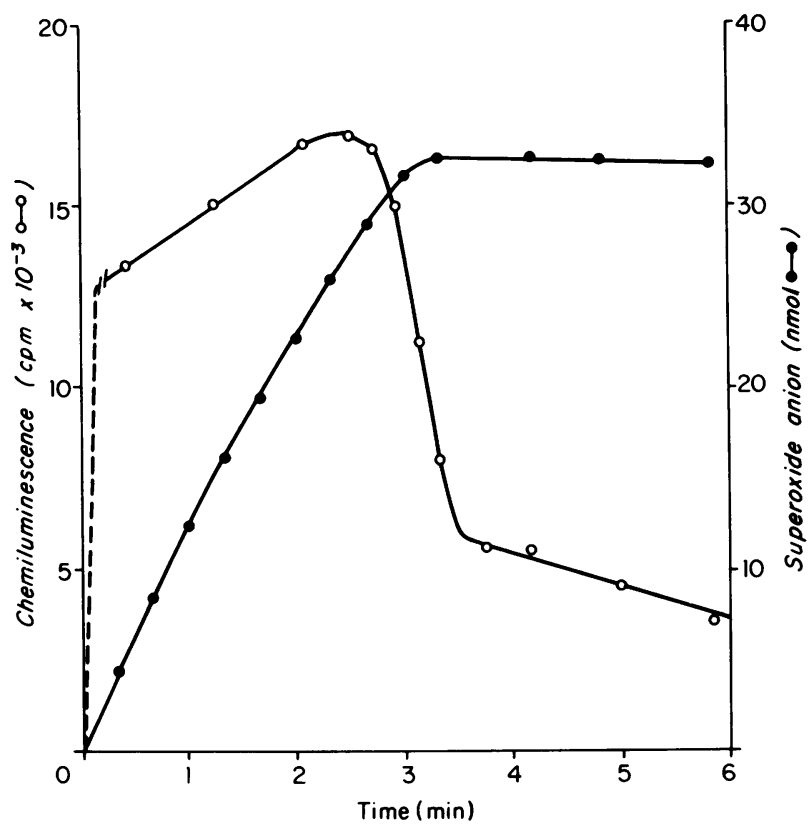

FigURE 6 Relationship of superoxide production to chemiluminescence by the xanthine oxidase system. For chemiluminescence $(O)$ the conditions were as described in Table $\mathrm{V}$ (complete system) except that the xanthine oxidase concentration was $0.074 \mathrm{mg} / \mathrm{ml}$. For superoxide anion assay (๑) zymosan and serum were omitted and cytochrome $c$ $1 \mathrm{mM}$ added.

chloride ${ }^{3}$ raising the possibility that this excited state is responsible in part either directly or indirectly for the light emission. Chemiluminescence in the presence of zymosan, in contrast to that in its absence, was only partially inhibited by the deletion of chloride suggesting that the light emission is not due entirely to the formation of singlet oxygen by the $\mathrm{H}_{2} \mathrm{O}_{2}$-hypochlorite system; the direct oxidation of zymosan by $\mathrm{MPO}$ and $\mathrm{H}_{2} \mathrm{O}_{2}$ may be partially responsible. It is assumed that the peroxidase system or the singlet oxygen formed by it converts a zymosan structural component to an electronically excited state which decays with light emission.

The involvement of MPO-mediated reactions in the light emission by intact leukocytes is suggested by its halide dependence with the relative effectiveness of the halides being similar in PMNs and the cell-free MPO system $\left(\mathrm{Br}^{-}>\mathrm{Cl}^{-}>\mathrm{I}[24]\right)$, by the decreased chemiluminescence of MPO-deficient leukocytes (Fig. 5) and by the inhibition of the chemiluminescence of normal leukocytes by azide (33, Fig. 5). That this effect of azide is due largely to the inhibition of peroxidase is suggested by the greatly reduced effect of azide on light emission by MPO-deficient leukocytes. Azide has been reported to react directly with singlet oxygen (34), and the inhibition observed with MPO-deficient cells may

\footnotetext{
${ }^{3}$ Rosen, H., and S. Klebanoff. Unpublished data.
}

therefore result in part from a direct quenching effect of azide. Alternatively, azide may affect enzymes other than MPO in these cells with an inhibition of light emission. It should be kept in mind that although MPO is absent from neutrophils and monocytes in hereditary MPO deficiency, eosinophils contain their normal complement of peroxidase. Eosinophils emit light when incubated with zymosan and serum under the same conditions as employed in Fig. 4, and this chemiluminescence is inhibited by $1 \mathrm{mM}$ azide and $94 \mu \mathrm{g} / \mathrm{ml}$ superoxide dismutase (human eosinophils [96-98\%]-cpm 20 min after the addition of particles: resting, 5,300; phagocytosis, 57,500; phagocytosis + azide, 20,300; phagocytosis + superoxide dismutase, 15,700.4) The MPO-deficient cell suspension contains small numbers of eosinophils which thus may contribute to the azide-inhibitable chemiluminescence.

Chemiluminescence by normal and MPO-deficient PMNs is also strongly inhibited by superoxide dismutase $(12,35,36$, Fig. 5), suggesting a requirement for the superoxide anion for optimal light emission. A quenching effect of superoxide dismutase on $\mathrm{O}_{2}{ }^{-}$-independent chemiluminescence, possibly due to a direct effect on singlet oxygen, has been proposed $(37,38)$, although a number of investigators (39-42) have questioned this conclusion. Further, superoxide dismutase reacts with $\mathrm{H}_{2} \mathrm{O}_{2}$ to produce chemiluminescence and peroxidation (43). It remains unclear therefore whether superoxide dismutase inhibits chemiluminescence entirely by its effect on $\mathrm{O}_{2}^{-}$.

Potassium superoxide and superoxide generating systems, e.g., xanthine oxidase, emit light, and this chemiluminescence is inhibited by superoxide dismutase (40, $44,45)$. We report here an increase in light emission on the addition of zymosan and serum to the xanthine oxidase system. Chemiluminescence by the xanthinexanthine oxidase-serum-zymosan system is markedly decreased by superoxide dismutase but is not inhibited by azide; indeed, azide has a small but significant stimulatory effect on this reaction. The mechanism of the superoxide anion-dependent chemiluminescence is not clear. It was proposed by Khan (46) that the light emission from potassium superoxide in aqueous solution is mediated by singlet oxygen, suggesting that the spontaneous dismutation of $\mathrm{O}_{2}^{-}$results in the formation of oxygen in the exited state, whereas superoxide dismutase-catalyzed dismutation does not. However, the formation of singlet oxygen during the spontaneous dismutation of $\mathrm{O}_{2}^{-}$has recently been questioned $(29,32)$ based on the inability to demonstrate singlet oxygen dependent chemical reactions. In some systems light emission is inhibited by both superoxide dismutase and catalase and is increased by $\mathrm{H}_{2} \mathrm{O}_{2}(44)$. The mechanism proposed

\footnotetext{
' Rosen, H., D. Durack, and S. Klebanoff. Unpublished data.
} 
was the interaction of superoxide and $\mathrm{H}_{2} \mathrm{O}_{2}$ to form hydroxyl radicals and the reaction of $\mathrm{OH} \cdot$ with $\mathrm{O}_{2}^{-}$to form oxygen in the excited state. Recent evidence has suggested that singlet oxygen formation by the xanthine oxidase system is the result of the direct interaction of $\mathrm{O}_{2}^{-}$and $\mathrm{H}_{2} \mathrm{O}_{2}$ (reaction $b$ ) and is independent of $\mathrm{OH}$. (47). In our studies chemiluminescence by the xanthine oxidase system was inhibited by catalase, mannitol and ethanol; however their inhibitory effect, in contrast to that of superoxide dismutase was small and benzoate was without effect suggesting that a hydroxyl radical-dependent mechanism can be only partially responsible for the light emission. Superoxide dismutase-inhibitable light emission could result from the direct reaction of $\mathrm{O}_{2}^{-}$with a chemical acceptor with the formation of an excited intermediate which decays with light emission (48). Although the exact mechanism is uncertain, the increase in chemiluminescence on the addition of serum and zymosan to the xanthine oxidase system (Table V) is compatible with the excitation of serum and/or zymosan components by $\mathrm{O}^{-}$.

These studies suggest that light emission by intact PMNs is dependent on both MPO and $\mathrm{O}_{2}^{-}$dependent reactions. Since zymosan is the ingested particle in the intact cell system and since light emission by both the MPO and xanthine oxidase model systems is increased by its addition, it seems reasonable to assume that excitation of zymosan is a major source of chemiluminescence in the intact PMN. This excitation may be induced by singlet oxygen, by superoxide anion or be the consequence of the oxidation of zymosan components by MPO and $\mathrm{H}_{2} \mathrm{O}_{2}$. Excitation of other cellular components or the relaxation of singlet oxygen also may contribute to the light emission by intact PMNs. During the early postphagocytic period, chemiluminescence by normal PMNs is inhibited by azide and is low in the leukocytes of patients with hereditary MPO deficiency. The microbicidal activity of MPO-deficient leukocytes also is low during this period, thus implicating MPO in both killing and light emission. Microbicidal activity of MPO-deficient leukocytes increases with prolonged incubation. Many of the parameters of the metabolic burst (oxygen consumption, glucose $\mathrm{C}-1$ oxidation, formate oxidation, superoxide anion formation) are increased in MPO deficiency, and an increase in oxygen consumption and glucose $\mathrm{C}-1$ oxidation by treatment of normal leukocytes with peroxidase inhibitors (azide, cyanide) has been observed $(5,21)$. This suggests that when MPO is inhibited or absent, oxygen consumption and those metabolic events dependent on it are increased. Perhaps among these are MPO-independent microbicidal activity and light emission. It should be emphasized that the correlation between light emission and microbicidal activity in normal and MPO-deficient leukocytes, although compatible with, does not necessarily implicate an electroni- cally excited state (e.g., singlet oxygen) as the microbicidal agent. Excitation may be a consequence of or an innocent bystander to the microbicidal process.

\section{ACKNOWLEDGMENTS}

This project was supported in part by U. S. Public Health Service grants AI07763, HD02266, and CA18354.

\section{REFERENCES}

1. Klebanoff, S. J. 1975. Antimicrobial mechanisms in neutrophilic polymorphonuclear leukocytes. Semin. Hematol. $12: 117-142$.

2. Lehrer, R. I., and M. J. Cline. 1969. Leukocyte myeloperoxidase deficiency and disseminated candidiasis: the role of myeloperoxidase in resistance to Candida infection. J. Clin. Invest. 48: 1478-1488.

3. Lehrer, R. I., J. Hanifin, and M. J. Cline. 1969. Defective bactericidal activity in myeloperoxidase-deficient human neutrophils. Nature (Lond.). 223: 78-79.

4. Klebanoff, S. J. 1970. Myeloperoxidase: contribution to the microbicidal activity of intact leukocytes. Science (Wash. D. C.). 169 : 1095-1097.

5. Klebanoff, S. J., and C. B. Hamon. 1972. Role of myeloperoxidase-mediated antimicrobial systems in intact leukocytes. J. Reticuloendothel. Soc. 12: 170-196.

6. Fridovich, I. 1974. Superoxide dismutases. $A d v$. Enzymol. Relat. Areas. Mol. Biol. $41: 35-97$.

7. Gregory, E. M., F. J. Yost, Jr., and I. Fridovich. 1973. Superoxide dismutases of Escherichia coli: Intracellular localization and functions. J. Bacteriol. 115: 987-991.

8. Yost, F. J., Jr., and I. Fridovich. 1974. Superoxide radicals and phagocytosis. Arch. Biochem. Biophys. 161: 395-401.

9. Babior, B. M., R. S. Kipnes, and J. T. Curnutte. 1973. Biological defense mechanisms. The production by leukocytes of superoxide, a potential bactericidal agent. $J$. Clin. Invest. 52: 741-744.

10. Curnutte, J. T., and B. M. Babior. 1974. Biological defense mechanisms. The effect of bacteria and serum on superoxide production by granulocytes. J. Clin. Invest. 53: 1662-1672.

11. Weening, R. S., R. Wever, and D. Roos. 1975. Quantitative aspects of the production of superoxide radicals by phagocytizing human leukocytes. J. Lab. Clin. Med. $85: 245-252$.

12. Johnston, R. B., Jr., B. B. Keele, Jr., H. P. Misra, J. E. Lehmeyer, L. S. Webb, R. L. Baehner, and K. V. Rajagopalan. 1975. The role of superoxide anion generation in phagocytic bactericidal activity. Studies with normal and chronic granulomatous disease leukocytes. J. Clin. Invest. 55 : 1357-1372.

13. Allen, R. C., R. L. Stjernholm, and R. H. Steele. 1972. Evidence for the generation of an electronic excitation state(s) in human polymorphonuclear leukocytes and its participation in bactericidal activity. Biochem. Biophys. Res. Commun. 47: 679-684.

14. Kearns, D. R. 1971. Physical and chemical properties of singlet molecular oxygen. Chem. Rev. 71: 395-427.

15. Wilson, T., and J. Hastings. 1970. Chemical and biological aspects of singlet excited molecular oxygen. Photophysiology. 5 : 49-95.

16. Krinsky, N. I. 1974. Singlet excited oxygen as a mediator of the antibacterial action of leukocytes. Science. (Wash. D. C.). 186: 363-365. 
17. Agner, K. 1958. Crystalline myeloperoxidase. Acta Chem. Scand. 12: 89-94.

18. Worthington Enzyme Manual. 1972. Worthington Biochemical Corp., Freehold, N. J. Page 43.

19. Massey, V. 1959. The microestimation of succinate and the extinction coefficient of cytochrome C. Biochim. Biophys. Acta. 34: 255-256.

20. Clark, R. A., S. J. Klebanoff, A. B. Einstein, and A. Fefer. 1975. Peroxidase- $\mathrm{H}_{2} \mathrm{O}_{2}$-halide system: cytotoxic effect on mammalian tumor cells. Blood. 45: 161-170.

21. Klebanoff, S. J., and S. H. Pincus. 1971. Hydrogen peroxide utilization in myeloperoxidase-deficient leukocytes: a possible microbicidal control mechanism. J.Clin. Invest. 50: 2226-2229.

22. Curnutte, J. T., D. M. Whitten, and B. M. Babior. 1974 Defective superoxide production by granulocytes from patients with chronic granulomatous disease. N. Engl. J. Med. 290: 593-597.

23. Stjernholm, R. L., R. C. Allen, R. H. Steele, W. W. Waring, and J. A. Harris. 1973. Impaired chemiluminescence during phagocytosis of opsonized bacteria. Infect. Immun. $7:$ 313-314.

24. Allen, R. C. 1975. Halide dependence of the myeloperoxidase mediated antimicrobial system of the polymorphonuclear leukocyte in the phenomenon of electronic excitation. Biochem. Biophys. Res. Commun. 63: 675683.

25. Allen, R. C. 1975. The role of $\mathrm{pH}$ in the chemiluminescent response of the myeloperoxidase-halide- $\mathrm{HOOH}$ antimicrobial system. Biochem. Biophys. Res. Commun. 63: 684-691.

26. Salin, M. L., and J. M. McCord. 1975. Free radicals and inflammation. Protection of phagocytosing leukocytes by superoxide dismutase. J. Clin. Invest. 56: 1319-1323.

27. Klebanoff, S. J., R. A. Clark, and H. Rosen. 1976. Myeloperoxidase-mediated cytotoxicity. In Cancer Enzymology. J. Schultz and F. Ahmad, editors. Academic Press Inc., New York. In press.

28. Khan, A. U., and M. Kasha. 1963. Red chemiluminescence of molecular oxygen in aqueous solution. J. Chem. Phys. 39 : 2105-2106.

29. Nilsson, R., and D. R. Kearns. 1974. Role of singlet oxygen in some chemiluminescence and enzyme oxidation reactions. J. Phys. Chem. 78: 1681-1683.

30. Agner, K. 1958. Peroxidative oxidation of chloride ions. Proc. Fourth Int. Congr. Biochem. 15: 64.

31. Paul, K. G. 1963. Peroxidases. In The Enzymes. P. D. Boyer, H. Lardy and K. Myrbäck, editors. Academic Press Inc., New York. 2nd edition. 8: 227-274.

32. King, M. M., E. K. Lai, and P. B. McCay. 1975. Singlet oxygen production associated with enzyme-catalyzed lipid peroxidation in liver microsomes. J. Biol. Chem. 250: 6496-6502.

33. Allen, R. C. 1973. Studies on the generation of electronic excitation states in human polymorphonuclear leukocytes and their participation in microbicidal activity. Disserta- tion. Tulane University, New Orleans, University Microfilms 74-291.

34. Hasty, N., P. B. Merkel, P. Radlick, and D. R. Kearns. 1972. Role of azide in singlet oxygen reactions: reaction of azide with singlet oxygen. Tetrahedron Lett. 49-52.

35. Webb, L. S., B. B. Keele, Jr., and R. B. Johnston, Jr. 1974. Inhibition of phagocytosis-associated chemiluminescence by superoxide dismutase. Infect. Immun. 9: 10511056.

36. Allen, R. C., S. J. Yevich, R. W. Orth, and R. H. Steele. 1974. The superoxide anion and singlet molecular oxygen: Their role in the microbicidal activity of the polymorphonuclear leukocyte. Biochem. Biophys. Res. Commun. 60: 909-917.

37. Paschen, W., and U. Weser. 1973. Singlet oxygen decontaminating activity of erythrocuprein (superoxide dismutase). Biochim. Biophys. Acta. 327: 217-222.

38. Paschen, W., and U. Weser. 1975. Problems concerning the biochemical action of superoxide dismutase (erythrocuprein). Hoppe-Seyler's Z. Physiol. Chem. 356: 727737.

39. Hodgson, E. K., and I. Fridovich. 1974. The production of superoxide radical during the decomposition of potassium peroxochromate (V). Biochemistry. 13: 38113815 .

40. Goda, K., T. Kimura, A. L. Thayer, K. Kees, and A. P Schaap. 1974. Singlet molecular oxygen in biological systems : non-quenching of singlet oxygen-mediated chemiluminescence by superoxide dismutase. Biochem. Biophys. Res. Commun. 58: 660-666.

41. Schaap, A. P., A. L. Thayer, G. R. Faler, K. Goda, and T. Kimura. 1974. Singlet molecular oxygen and superoxide dismutase. J. Am. Chem. Soc. 96: 4025-4026.

42. Michelson, A. M. 1974. Is singlet oxygen a substrate for superoxide dismutase? No. FEBS (Fed. Eur. Biochem. Soc.) Lett. 44: 97-100.

43. Hodgson, E. K., and I. Fridovich. 1975. The interaction of bovine erythrocyte superoxide dismutase with hydrogen peroxide: chemiluminescence and peroxidation. Biochemistry. 14 : 5299-5303.

44. Arneson, R. M. 1970. Substrate-induced chemiluminescence of xanthine oxidase and aldehyde oxidase. Arch Biochem. Biophys. $136: 352-360$.

45. Finazzi Agrò, A., C. Giovagnoli, P. De Sole, L. Calabrese, G. Rotilio, and B. Mondovi. 1972. Erythrocuprein and singlet oxygen. FEBS (Fed. Eur. Biochem. Soc.) Lett. 21: 183-185.

46. Khan, A. U. 1970. Singlet molecular oxygen from superoxide anion and sensitized fluorescence of organic molecules. Science (Wash. D. C.). 168: 476-477.

47. Kellogg, E. W., III, and I. Fridovich. 1975. Superoxide, hydrogen peroxide, and singlet oxygen in lipid peroxidation by a xanthine oxidase system. J. Biol. Chem. 250: 8812-8817.

48. Greenlee, L., I. Fridovich, and P. Handler. 1962. Chemiluminescence induced by operation of iron-flavoproteins. Biochemistry. 1: 779-783. 